\title{
Medical Borders: Historical, Political, and Cultural Analyses
}

\section{Nadav Davidovitch}

Center for the History and Ethics of Public Health, Mailman School of Public Health, Columbia University, and Department of Health Systems Management, Ben Gurion University

Rakefet Zalashik

Skirball Department of Hebrew and Judaic Studies, New York University

Scientific medicine carries within it an inherent contradiction. On the one hand, given its general scientific inquiry into health and disease, their conditions, etiologies, and treatments, it makes a claim for universality. To justify this claim, at different times and in different places, scientific medicine has prioritized techniques such as the medical gaze and autopsies to assure its diagnoses; it has applied numerical methods in order to have a better grasp of diseases and their possible treatments; it has used laboratory analyses in order to understand life at its molecular level; and more recently it has introduced Randomized Clinical Trials (RCT) in order to generalize clinical treatments. On the other hand, contrary to its universalistic claims, scientific medicine sets up and reifies boundaries. It creates distinctions between the healthy and the sick and defines categories, such as gender and race, that have deep political and social meanings.

Various modern historical constructs - ranging from colonialism to nation building - are heavily based on medicine as a scientific discipline and on the medical profession and its practitioners. The nation-state as a modern construct needs well defined borders for its existence. Bio-medicine is vital to these processes. Colonial medicine has played an important role within an expansive ideological order of the empires, linked to the economic interests of the colonizers. As part of colonial logic, scientific medicine produces borders and distinctions between colonizers and colonized bodies as well as between Western knowledge and traditional local knowledge.

Medical borders exist not only between countries. Medical and epidemiological distinctions are also created between geographical and spatial levels within countries. Health disparities exist, as a by-product of medical borders, among and within neighborhoods and cities as well as across socio-economic strata. There are also disparities between professional levels among different health-care professions and between conventional, unconventional, or traditional healing systems.

The function of medicine to create authoritative standards that distinguish between the normal and the pathological body also generates another kind of border on 
the bodily level, expressed in individual lives as well as in collectives. Investigating this function as manifested in medical theory and practices is fertile ground for understanding scientific medicine and technological innovations in context. The medicalization of the body has been an important factor in critical analyses of medicine and public health practices during the last decades, exposing the disciplinary and oppressive sides of modern medicine.

As medicine has played an important role in creating and contesting borders throughout history and even more so now in an increasingly global context, this collection of articles seeks to explore new ways of understanding "medical borders." Modern history has witnessed the formation and obliteration of borders with the movement of immigrants, health-care workers, diseases, and scientific ideas. These processes of movement and border crossings, of people, technologies, and concepts, bear important implications for understanding the history of medicine and public health and its role in society.

Historians have long sought to make sense of the spectacular, if contested, consolidation and legitimation of the attempts of nation-states to regulate and discipline bodies and minds. ${ }^{1}$ Only recently, however, have new studies begun to point out the significant role of science and medicine in the formation of national identity as well as in the building of nations (Anderson 2003; Bashford 2004). This role of science and medicine has been especially significant for immigrant-receiving nations (Shah 2001; Fairchild 2003). Other studies emphasize the role of border crossing in the development of scientific disciplines or technological innovations, showing how ideas and technologies are applied and influenced by transmission across borders. ${ }^{2}$

Interestingly, although, as argued, "medical borders" are established in many areas of our life, medicine and health are usually considered to be a-political. In sharp contrast to the perception of "medical borders," the slogan "diseases have no borders" has been repeated on various occasions. This seemingly neutral, a-political image is often raised in public rhetoric for various reasons. Medical scientists tend to emphasize the universal qualities of medicine even though medical theories and practices are deeply embedded in social, cultural, and political contexts. Effacing borders helps to promote medicine's universalistic claims and also endorses humanitarian goals when political conflicts might interfere with public health endeavors. Health-care workers can point to the danger of the spread of disease when they wish to convince policy makers to implement their programs along both sides of a national border or within areas

\footnotetext{
${ }^{1}$ For an introduction to the relationship among the rise of the modern state, medicine, and public health in several countries, see Dorothy Porter's discussion in Porter 1999, 63-231. On health and colonialism, see Worboys 2000, 51-66.

${ }^{2}$ In Jennifer Stanton's edited volume, Aya Takahashi (nursing in Japan), Roberta Bivins (acupuncture in Britain), and Thomas Schlich (operative bone fracture in Switzerland) analyze three different case studies of the uptake of medical innovations and technologies in their national contexts. Their discussions show the fundamental transformation of the various technologies following the border crossing and the "translation" process (Stanton 2002).
} 
of conflict. The use of medicine, as any other humanitarian practice, can indeed be employed according to its promoter's beliefs. The slogan, "diseases have no borders" can be used in campaigns against bioterrorism and emerging infectious diseases, which includes the call for securing borders and improving laboratory methods, or in health promotion endeavors to ease health disparities where solutions are sought more in social and cultural perspectives (King 2004).

National Immunization Days (NID), which are currently conducted as part of the Global Polio Eradication Initiative launched in 1988 by the World Health Organization (WHO) in regions of conflict in Africa and Asia, testify that unintended consequences may result from well-meant public health campaigns across borders. Armed groups are many times willing to hold fire in order to permit health-care workers to perform public health activities in areas of conflicts and war. Nevertheless, these good intentions can create tensions between health-care workers and the local population as exemplified in recent fears of local populations in Nigeria that contaminated polio vaccines were used by Westerners in order to sterilize the community. ${ }^{3}$

Indeed, medicines distributed across borders are presented as exported goods intended to help "third world countries" and hence serve as useful means for modernization. Indeed the use of medical treatments and technologies - ranging from the relatively sophisticated anti-HIV drugs or vaccinations to simple yet crucial measures such as clean water for drinking and washing - could save millions of lives all over the world and narrow the gap between rich and poor countries in regard to health. Unfortunately, the practical implementation on the ground is usually more complicated than just bringing goods to poor countries. In some cases health care or public health measures can cause harm if they are introduced without taking into account the various conditions prevailing in different climates, places, cultures, and societies.

Moving beyond the dichotomy of "center" and "periphery" that has dominated the recent historiography of the non-Western world, the articles presented here explore the exchange of ideas and practices from one geographical space to another, between colonizers and the colonized, and between various colonial spheres. ${ }^{4}$ In addition to questioning current conceptions of the geography and politics of knowledge, we hope to challenge conventional chronological divisions between the colonial and the postcolonial. The particular themes explored in this volume are health and migration, the global movement of people and scientific ideas, science and medicine, as well as refugees and war.

\footnotetext{
${ }^{3}$ For a thought-provoking pictorial documentation of recent efforts to eradicate polio, capturing the tensions between the good will of the vaccinators and the coercive aspects of public health, see Saldago 2005, 211-233. Saldago accompanied teams of health-care workers and volunteer vaccinators on NIDs that were organized in 2001 in five countries where polio was still endemic - Democratic Republic of Congo (DRC), India, Pakistan, Somalia, and Sudan.

${ }^{4}$ On Western medicine encounters with non-Western local contexts, their acceptance, translation and resistance, see Cunningham and Andrews 1997.
} 


\section{Health and migration}

Despite the racial overtones in the rhetoric of "hygiene" and "cleansing" that is ubiquitous in most medical immigration policies of the past one hundred years, as several contributors in this volume show, there is a long history of tension in immigrant-receiving nations between the impulse to exclude and the impulse to include immigrants in the population, the workforce, or the culture. This tension has made it necessary to convey clearly to newcomers and to the general public what nations expect from immigrants - both by coercion and by persuasion - as actual and potential citizens. Immigrants have been and still are needed for the building of societies, economies, and cultures.

\section{"Global" movement of people and scientific ideas}

The vast movements of populations, health care workers, practices, technologies, diseases and epidemics - throughout material and immaterial borders, agreed or contested lines - are important factors to be considered for a more complete understanding of future dynamics such as the reshaping of social and cultural practices of individual communities associated with empire and the movements of ideas and knowledge beyond national and imperial borders.

\section{Science and medicine}

Analyzing the theoretical and practical manifestations of science and medicine enables us to examine the space between rhetoric and practice and allows us to understand the encounters between different knowledge systems as they are expressed in practice; the content of the tension between the European and the American scientific ideal of universal knowledge that reached its peak after World War II; and the limitations and new outcomes involved in medicine's geographical and cultural extension.

\section{Refugees and war}

During the twentieth century we have witnessed several disruptive wars and conflicts. The crises related to the displacement of people, ethnic cleansing, war, and genocide had important health dimensions. The collapse of borders and the resulting tensions were accompanied by medical and public health problems that needed to be resolved. Here we examine the approach of health officials and scientists to the questions of refugees, displaced persons, and concentration camp survivors. We look the social and political context in which they developed their public health responses and research. Military physicians as well as other health-care professionals all over the world struggled 
with these issues. This collection of articles shows how their different actions and reactions were shaped in different times and places.

The first three articles in this topical issue offer different perspectives on the role of medicine, science, medical borders, and immigration. Although one can find some common features in the way potential immigrants were treated and perceived in Australia, the United States, and Argentina from the last quarter of the nineteenth century to the first decades of the twentieth century, the cases presented by Krista Maglen (Australia), Julia Rodriguez (Argentina), and Amy Fairchild (the United States) give a sharp picture of the unique characteristics that were forged by the specific national, political, and economic interests, needs, and conditions of each country.

Krista Maglen shows how quarantine policy and practice in nineteenth-century Australia were experienced from the perspective of the quarantined immigrants, including especially healthy immigrants who were held in quarantine stations. In contrast to the more common historical research that has reviewed the official story told from the medical establishment point of view, Maglen examines personal diaries and letters that show how quarantine was used as a defense against infection and in many cases became a tool to control immigration according to race and class. In general, the detention component of quarantine was accepted by the immigrants in the commonly held belief that epidemic diseases were contagious and that quarantine was a means to break the lines of transmission. Resistance of immigrants was raised only in cases where this "rationale" was violated such as when a duration of quarantine was perceived as too long in relation to the nature of the disease or the number of the people who suffered from it, when sick people received inadequate medical treatment, when the conditions in quarantine were unreasonable, or when Australian officials who were supposed to enforce quarantine themselves violated its principles.

Amy Fairchild explores the changing notion of health and disease among publichealth officers responsible for immigration into the United States. In revisiting the function and meaning of the medical examination, Fairchild argues that while touted and, indeed, initially intended as an important exclusionary tool, the assembly line that processed some 25 million immigrants between 1890 and 1920 was, for the vast majority, part of a process not of exclusion, but inclusion. Immigrant medical inspection served as the inaugural event in the life of the new industrial labor force; it worked to absorb immigrants into American industrial life and transform them into efficient industrial citizens with "proper" industrial values and attitudes. Only when immigrants failed to conform to societal expectations about the industrial worker did the medical exam exclude them at the nation's borders. In practice those deemed unfit were mainly from non-white Asian origins coming to the west coast. Her analysis shows the development of public-health officers' practices and their ways of screening health problems at a glance. These practices helped to draw the line between normal and diseased immigrants. 
Julia Rodriguez examines the role of physicians as gatekeepers in selecting immigrants from Europe to Argentina after 1870. Argentinean authorities hoped to attract immigrants from northern Europe and allowed them unrestricted entrance, while less welcome immigrants from Italy, Spain, and Eastern Europe made up the majority of immigrants flowing into the country. Argentina's attitude towards immigration was ambivalent: on the one hand, the nation perceived immigrants as an important factor of industrialization, and on the other hand, they feared that the great wave of migration from southern Europe would introduce negative aspects of modernization: poverty, disease, crime, and socio-political instability. Rodriguez shows that the officials responsible for the legal and practical aspects of immigration management - most of them physicians who were using "scientific" measurable criteria for inspecting and identifying the desirable traits of the "right" immigrant were actually led by racist white-elite concepts and they used science to justify their exclusive and inclusive policies. Moreover, she detects a dynamic change in the process of selection. The earlier approach toward the issue of potential immigration was empirical and later it became normative. From 1910, due to the gap between the rhetoric and the reality, and due to the failure of selective usage and eugenic means, a new policy of assimilation of the newcomer was adopted.

A different perspective of medical borders can be found in the article by Sandy Sufian on Zionist malariologists in Mandatory Palestine. The borders Sufian describes are first of all geographic and ethnic. She focuses on the specific ways in which these scientists maintained a dichotomy between the transnational and local aspects of their work. The scientists supported this dichotomy with nationalist concerns that also created boundaries between Arab and Jewish populations in Palestine. In contrast to scientists in other regions who were working for colonial empires according to an imperial science imported from the "center" (many times by military physicians), Zionist malaria scientists were immigrant civilians themselves who strove to achieve national goals and international recognition. In their emphasis on the national aspects of their work, their battle against malaria in Palestine was orientated towards the particularities of the country, while international scientific recognition would prove their legitimacy as a nation and their credibility in the European colonial world.

The article by Paul Weindling discusses the medical treatment of former BergenBelsen concentration camp prisoners by the British troops. His concept of "medical border" illuminates aspects different from the previous articles. Weindling deals with the mistreatment given by the British to these prisoners and argues that many lives could have been saved if the British had used different strategies of control against typhus and other contagious diseases. He also deals with the treatment of other health issues, such as the emergency feeding and the treatment of psychiatric cases. In addition, he gives evidence to show that medical control was used to detain ex-prisoners and later to select candidates for migration to the United States, Western Europe, and Mandatory Palestine, using mechanisms for selection that served the interests of the receiving countries. 
In the last article, Rakefet Zalashik and Nadav Davidovitch deal with another aspect of medical borders, albeit consistent with the thematic of Weindling's article. They examine the activities of two psychiatric delegations, American and Palestinian, which were sent to camps in Cyprus where Jewish illegal immigrants to Palestine, most of them holocaust survivors, were detained by the British. The purpose of the medical delegations was to screen the camps' inhabitants and to propose a mental-health program for their life in Palestine. This case study highlights the interaction among people, refugees as well as health-care workers, and the transmission of knowledge and professional expertise across the ocean, which shaped medical perceptions of the Jewish DP problem and its solution, from both a Zionist and an American perspective.

The articles presented here problematize the notion of "borders" (spatial, geographical, conceptual, social, national, and epidemiological) and their medicalization. This collection cannot exhaust all possibilities and potential for research into the notion of medical borders. Many localities are missing, most notably the African continent, which is involved in many projects involving medical borders in the colonial and post-colonial context. Medical borders were not "invented" recently; they have a long history and will continue to be constructed and transgressed. Studying the context and history of their creation, destruction, or effacement is a field of vast potential for those interested in the history of science, medicine, public health, and other disciplines as well. Borders have crucial implications for our daily life. Therefore, understanding the medicalization of borders and questioning them, both in the global and local context, is important not only for historians of medicine. We hope that this collection will initiate a fruitful discussion about the potential implications of historicizing medical borders not only for medical professionals, historians, and sociologists of medicine and public health, but also for political scientists and scholars from various disciplines who are not only interested in medicine per se. Thus, the topic of medical borders can be abstracted to broader social phenomena that embody social, cultural, political, and economic issues.

\section{Acknowledgments}

We would like to thank Amy Fairchild, Alexandre Métraux, and Sandy Sufian for their helpful comments.

\section{References}

Anderson, Warwick. 2003. The Cultivation of Whiteness: Science, Health, and Racial Destiny in Australia. New York: Basic Books.

Bashford, Alison. 2004. Imperial Hygiene: A Critical History of Colonialism, Nationalism and Public Health. Basingstoke: Palgrave Macmillan. 
Cunningham, Andrew and Bridie Andrews, eds. 1997. Western Medicine as Contested Knowledge. Manchester: Manchester University Press.

Fairchild, Amy L. 2003. Science at the Borders: Immigrant Medical Inspection and the Shaping of the Modern Industrial Labor Force. Baltimore and London: Johns Hopkins University Press.

King, Nicholas. 2004. "The Scale Politics of Emerging Diseases." Osiris 19:62-76.

Porter, Dorothy. 1999. Health, Civilization and the State: A History of Public Health from Ancient to Modern Times. London and New York: Routledge.

Saldago, Sebastião. 2005. "The End of Polio." In The Body at Risk: Photography of Disorder, Illness and Healing, edited by Carol Squires, 211-233. New York, Berkeley, Los Angeles, London: International Center of Photography, Milbank Memorial Fund, University of California Press.

Shah, Nayan. 2001. Contagious Divides: Epidemics and Race in San Francisco's Chinatown. Berkeley: University of California Press.

Stanton, Jennifer, ed. 2002. Innovations in Health and Medicine: Diffusion and Resistance in the Twentieth Century. London and New York: Routledge.

Worboys, Michael. 2000. "Colonial Medicine." In Companion to Medicine in the Twentieth Century, edited by Roger Cooter and John Pickstone, 51-66. London and New York: Routledge. 